\title{
Developing the Saegusa-Ito Cyclisation for the Synthesis of Difluorinated Cyclohexenones
}

\author{
Prof. Dr. Jonathan M. Percy, ${ }^{\text {aa }}$ Adam W. McCarter, ${ }^{a}$ Alan L. Sewell, ${ }^{a}$ Nikki Sloan, ${ }^{a}$ Dr. Alan R. \\ Kennedy, ${ }^{a}$ and Dr. David J. Hirst. ${ }^{b}$
}

Abstract: Palladium(II)-catalysed cycloalkenylation (Saegusa-lto cyclisation) has been used for the first time to transform difluorinated silylenol ethers to difluorinated cycloalkenones under mild conditions. The silylenol ether precursors were prepared in two high-yielding steps from trifluoroethanol, and cyclised in moderate to good yields. A combination of air and copper(I) chloride in acetonitrile achieved the turnover of the initial palladium(II) salt, while the provision of an oxygen atmosphere ensured more rapid reaction. Annulations required a minimum level of substitution on the chain, but failed when the alkene was substituted. Annelations allowed a range of $\mathrm{n}, 6$-bicyclic systems to be prepared and afforded three products in which heterocycles were fused to the new cyclohexenone. The least substituted system explored underwent cyclisation followed by terminal oxidation to a cyclic enal, which corresponded to a Wacker product of unusual regiochemistry.

\section{Introduction}

The palladium-catalysed cycloalkenylation reaction or SaegusaIto cyclisation is a valuable tool for the construction of cyclic enones 2 (and or 3) from acyclic precursors 1 (Scheme 1) ${ }^{[1]}$ because of the considerable utility of cyclic enones, the reaction has been deployed strategically and widely in natural product synthesis. ${ }^{[2]}$ A recent example was provided by Jeker and

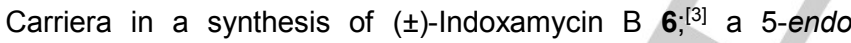
cyclisation of $\mathbf{4}$ to $\mathbf{5}$ secured a key 6,5-dicyclic precursor to the natural product. Recently, Reisman and co-workers have used related cyclisations (of silyl ketene acetals) in total syntheses of ent-kauranoids. ${ }^{[4]}$ The diene precursors to cyclisation are easyto-make, with kinetic enolate technology ensuring that the nucleophile can be placed accurately. While initial reactions used stoichiometric quantities of palladium(II) acetate, ${ }^{[5]}$ Toyota and Ihara $^{[6]}$ were able to develop catalytic procedures by carrying reactions out in DMSO under an atmosphere of oxygen. ${ }^{[7]}$ Cyclopentenone and cyclohexenone products are formed most commonly; Dénès and co-workers reported relatively few examples of annulations (and then only under stoichiometric $\operatorname{Pd}(\mathrm{II})$ conditions), but many more examples of annelative processes leading to vicinal and bridged ring fusions.

[a] Prof. Dr. Jonathan M. Percy, ${ }^{*}$ Adam W. McCarter, Alan L. Sewell, N. Sloan, Dr. Alan R. Kennedy

WestCHEM Department of Pure and Applied Chemistry, University of Strathclyde, Thomas Graham Building, 295 Cathedral Street,

Glasgow G1 1XL (UK). Fax: (+44) 0141-548-4822. E-mail: jonathan.percy@strath.ac.uk

[b] Dr. David J. Hirst

Flexible Discovery unit (FDU),

GlaxoSmithKline Medicines Research Centre,

Gunnels Wood Road, Stevenage,

SG1 2NY (UK). Fax: (+44) 01438762658

Email: david.j.hirst@gsk.com
The role of the $\mathrm{Pd}(\mathrm{II})$ is to bind to an alkenyl group and facilitate $\mathrm{C}-\mathrm{C}$ bond formation. Reductive elimination of an $\mathrm{HPdX}$ species releases $\operatorname{Pd}(0)$ into solution and re-oxidation is required to reinstate $\mathrm{Pd}(\mathrm{II})$.

Generic Saegusa-Ito cyclisation reaction

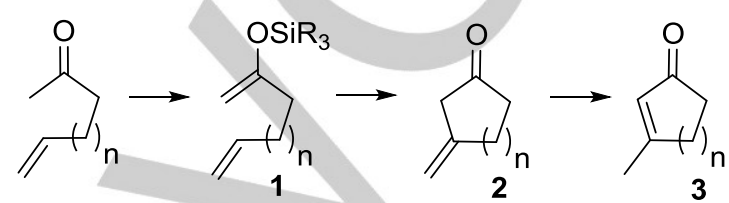

Conditions 1 to $2 \mathrm{Pd}(\mathrm{II})$, reoxidant, $\mathrm{n}=1$ or 2

Application in natural product synthesis

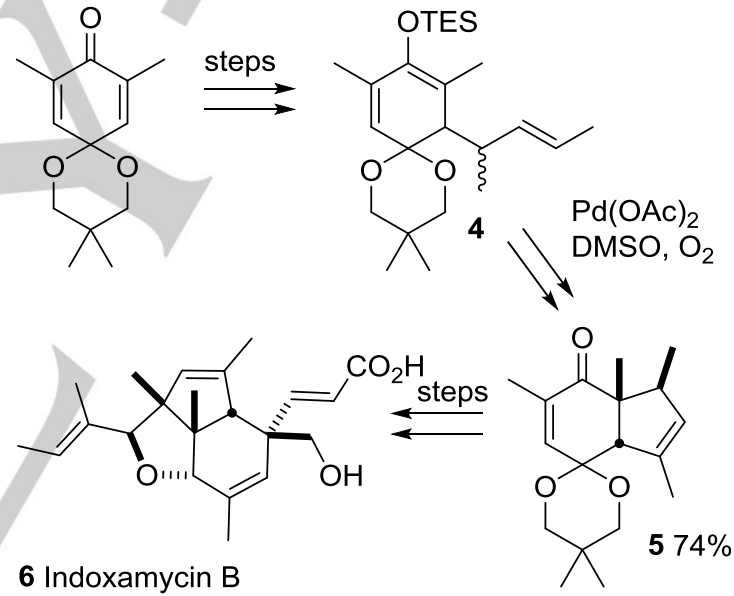

Scheme 1. Generic Saegusa-Ito cyclisation and an application in natural product synthesis.

We speculated that the reaction would admit difluorinated silyl enol ethers as nucleophiles. There were various reasons for our interest; methods for the construction of selectively fluorinated cyclic molecules from sustainable fluorocarbon starting materials are relatively limited with the fluorination of a cyclic alcohol or ketone with $\mathrm{DAST}^{[8]}$ or a related nucleophilic fluorinating agent ${ }^{[9]}$ the most commonly implemented method. The approach is exemplified by the preparation of cyclic difluoroketone ligands for protease active sites in Diederich's recent studies. ${ }^{[10]} A$ potentially significant recent development was reported by Amii and co-workers, using difluorocarbene transfer and cyclopropane ring-opening as the key transformation. ${ }^{[11]}$ However, annulation chemistry based on difluorinated building blocks is less well established. ${ }^{[11-12]}$ The published chemistry of difluorinated silyl enol ethers is developing, with Mukaiyamatype aldol reactions, ${ }^{[13]}$ including recent "on-water" examples, ${ }^{[14]}$ additions to iminium electrophiles ${ }^{[15]}$ and a recent $\mathrm{Pd}$-catalysed 
arylation. ${ }^{[16]}$ The latter example is relevant because one mechanism involves nucleophilic attack by the difluorinated silyl enol ether on a $\mathrm{Pd}(\mathrm{II})$ electrophile. Other workers have proposed that (arylpalladium)difluoroenolate complexes can be generated readily and undergo reductive elimination to release aryldifluoromethylcarbonyl derivatives. ${ }^{[17]}$

\section{Nucleophilic ketone fluorination}<smiles>O=C=CC1CCCCC1</smiles>

Carbene transfer/cyclopropane ring-opening<smiles>[R19]OC1=CCCC1</smiles>

\section{Saegusa-Ito cyclisation?}<smiles>[R18]OC(CCCC=C)=C(F)F</smiles>

Scheme 2. Strategies for the synthesis of difluorinated cyclohexanes

then addition to a $\gamma, \delta$-unsaturated aldehyde or ketone delivers lithium alkoxide 12. Carbamoyl transfer releases a difluoroenolate 13 which should react with silicon electrophiles through the hard oxygen affording 14 in a single pot (Scheme 3). The driving force for the reorganisation is the higher basicity of alkoxide oxygen (typical alcohol $\mathrm{pK}_{\mathrm{a}} 16-18$ in water) compared to enolate oxygen (typical alcohol $\mathrm{pK}_{\mathrm{a}} \mathrm{E}^{\mathrm{E}}$ 10-11 in water). ${ }^{[20]} \mathrm{We}$ used this chemistry to prepare a range of difluorinated molecules; difluoroallylic alcohols were isolated when we trapped 11 with an aldehyde, and used a boron Lewis acid to attenuate the carbamoyl transfer.

Difluoromethyl ketones were obtained from 11 and ketone electrophiles, and if the difluoroenolates were allowed to form before protic work-up. Trapping enolates 13 with a hard silicon electrophile looked likely to succeed and deliver the cyclisation precursors. We therefore began an exploration of this chemistry.Text Paragraph.

\section{Results and Discussion}

We chose 5-hexen-2-one $15 \mathrm{a}$ as a trial electrophile to explore the carbamoyl transfer and enolate formation (Table 1). After initial attempts to isolate trimethylsilyl enol ethers, which though formed in excellent conversion (by ${ }^{19} \mathrm{~F}$ NMR spectra of crude products) were too delicate to be purified properly, we found that triethylsilyl species could be prepared and purified in good yield from a palette of aldehyde and ketone electrophiles (Figure 1).<smiles>[R]C(=O)CCC([R])=C([R])[R]</smiles>

15a, $R^{1}=M e, R^{2}-R^{4}=H$ $15 b, R^{1}, R^{3}, R^{4}=M e, R^{2}=H$ $15 c, R^{1}=R^{2}=M e, R^{3}, R^{4}=H$<smiles>C=CCC([14CH3])(CC)C(C)=O</smiles>
$15 \mathrm{~g}, \mathrm{n}=1$
$15 \mathrm{~h}, \mathrm{n}=3$<smiles>[R17]CC(=CF)O[CH]C</smiles><smiles>C=CCC1CCCC1=O</smiles>

$15 i, n=1$; $15 \mathrm{j} n=2$; $15 k, n=3$<smiles>[R]C([R1])(C=O)CC=C</smiles>

$15 d, R^{1}=H$; $15 e, R^{1}=M e$

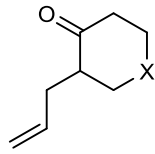

$151, X=0$; $15 \mathrm{~m}, X=\mathrm{NBoc}$

$15 n, X=S$ 15o, $X=\mathrm{SO}_{2}$<smiles>C=CCC(=C)C(C)=O</smiles>

$15 f$<smiles>C=CCC1=C(OC)CCCC1=O</smiles>

$15 p$

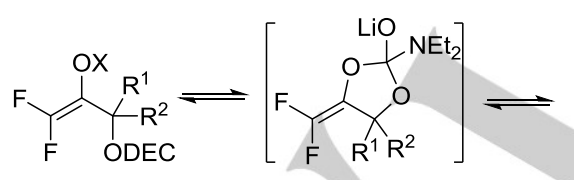

13, $\mathrm{X}=\mathrm{Li} ;$
$14, \mathrm{X}=\mathrm{SiR}_{3}$ $\mathrm{R}_{3} \mathrm{SiCl}$

Scheme 3. Proposed rapid (two-pot) synthesis of difluorinated silylenol ethers from trifluoroethanol 1.

Our metallated difluoroenol carbamate chemistry ${ }^{[19]}$ offered the opportunity of extremely concise construction of precursors to Saegusa-Ito cyclisation from trifluoroethanol 9; conversion to carbamate $\mathbf{1 0}$ followed by dehydrofluorination/lithiation to $\mathbf{1 1}$,
Figure 1. Electrophiles used to prepare difluorinated silyl enol ethers.

The strong base reagent could be generated in situ or commercial LDA could be used for convenience. Carefu temperature control during carbamate addition was essential because the initial dehydrofluorination/metallation is exothermic and the organolithium intermediate decomposes above $-65^{\circ} \mathrm{C}$ The period of warming from -78 to $0^{\circ} \mathrm{C}$, and the extended stirring overnight, allowed the addition and transcarbamoylation steps, and silylation of the enolate, to reach completion. Work up was facile (removal of THF, trituration with hexane and filtration through silica) and crude products, which usually had good ${ }^{19} \mathrm{~F}$ 
and ${ }^{1} \mathrm{H}$ NMR spectra, could be purified by normal phase flash column chromatography and stored for ca. 1 week in the refrigerator before decomposition began (Table 1).

$$
\begin{aligned}
& \text { DECO } \\
& \text { i) LDA, THF, }-78^{\circ} \mathrm{C} \\
& \text { ii) Electrophile, warm to } 0^{\circ} \mathrm{C} \\
& \text { iii) } \mathrm{Et}_{3} \mathrm{SiCl} \text {, warm to } 15^{\circ} \mathrm{C} \\
& { }_{\mathrm{ODEC}}^{\mathrm{R}^{2}} \\
& 16
\end{aligned}
$$

\begin{tabular}{|c|c|c|c|c|c|}
\hline Electrophile & Product & $\begin{array}{l}\text { Yield } \\
(\%)\end{array}$ & Electrophile & Product ${ }^{[c]}$ & $\begin{array}{l}\text { Yield } \\
(\%)\end{array}$ \\
\hline $15 a$ & $16 a$ & $67^{[a]}$ & $15 i$ & $16 i$ & 62 \\
\hline $15 b$ & $16 \mathrm{~b}$ & 63 & $15 \mathrm{j}$ & 16j & 71 \\
\hline $15 c$ & $16 c$ & 80 & $15 \mathrm{k}$ & $16 \mathrm{k}$ & 40 \\
\hline $15 d$ & $16 d$ & $63^{[b]}$ & 151 & 161 & $46^{[c]}$ \\
\hline $15 e$ & $16 \mathrm{e}$ & 67 & $15 \mathrm{~m}$ & $16 \mathrm{~m}$ & 57 \\
\hline $15 f$ & $16 f$ & $59^{[b]}$ & $15 n$ & $16 n$ & 69 \\
\hline $15 \mathrm{~g}$ & $16 \mathrm{~g}$ & 61 & 150 & 160 & $25^{[\mathrm{d}]}$ \\
\hline $15 \mathrm{~h}$ & $16 \mathrm{~h}$ & 38 & $15 p$ & $(-)$ & 0 \\
\hline
\end{tabular}

Table 1. Difluorinated silylenol ethers 16 prepared from 10.

[a] At 10 mmole scale (68\%), at 40 mmole scale (70\%). [b] At 10 mmole scale. [c] At $6.5 \mathrm{mmole} \mathrm{scale.} \mathrm{[d]} \mathrm{At} 4.8 \mathrm{mmol}$ scalle.

Typical reactions used 5 mmole of 10 , but the preparation of $16 a$ was scaled to 40 mmole with no reduction in yield $(11.0 \mathrm{~g}$ of $16 \mathrm{a}$, $70 \%$ after chromatography). The sequence was used to prepare silyl enol ethers 16a-o (preparation of the electrophiles is described in the Supporting Information). Electrophile 150 was extremely difficult to dry; even after 150 was heated for 1 week in a vacuum oven $\left(40{ }^{\circ} \mathrm{C} / 0.75 \mathrm{mmHg}\right)$, significant amounts of enol carbamate were returned from the reaction with 10 . The inability to fully dry $\mathbf{1 5 0}$ would account for the lower yield of $\mathbf{1 6 0}$. The only substrate which failed to undergo conversion to the silyl enol ether was dienone 15p. Unfortunately, organolithium reagent 11 failed to add to $15 p$, though ethenylmagnesium bromide adds to $15 \mathrm{p}$ in good yield at $\left.0{ }^{\circ} \mathrm{C}\right)$. $^{[21]}$ The cis- and transdiastereoisomeric adducts from $15 \mathrm{I}$ (formed in a $14: 86$ ratio by ${ }^{19} \mathrm{~F}$ NMR) could be separated chromatographically. The cyclisation of 16a was investigated with stoichiometric palladium acetate in the first instance. The solvent chosen was dimethylsulfoxide, ${ }^{[22]}$ which was sparged with pure oxygen immediately before use; reactions were run under an atmosphere (balloon pressure) of pure oxygen. Starting material was consumed completely and rapidly but product isolation was extremely difficult from the tarry and foul-smelling residue. When 16a was exposed to $10 \%$ palladium(II) acetate in acetonitrile, DFMK 17 (Figure 2) was formed as the major product (by ${ }^{19} \mathrm{~F}$ NMR) with distinguishable signals at -124.5 and $-126.3 \mathrm{ppm},{ }^{[19]}$ with only traces of $18 \mathrm{a}$. This result suggests strongly that a palladium electrophile binds at the silyl enol ether and converts it to a palladium enolate and triethylsilyl acetate.<smiles>C=CCCC(C)(OCC)C(=O)C(F)F</smiles>

Figure 2. Difluoromethyl ketone 17 formed from $16 \mathrm{a}$ in the presence of $\mathrm{Pd}(\mathrm{OAc})_{2}$.

Ketone formation requires a proton which could come from water formed by the reduction of dioxygen (coupled to the $\mathrm{HPdOAc} \rightarrow \mathrm{Pd}(\mathrm{OAc})_{2}$ re-cycle); hydrolysis of triethylsilyl acetate releases acetate to ligate the palladium, and should lead to the formation of hexaethyldisiloxane. We then examined a range of copper salts (summarised in Table 2). The expected oxidative recycling of $\mathrm{Pd}(0) \rightarrow \mathrm{Pd}(\mathrm{II})$ could be coupled with a $\mathrm{Cu}(\mathrm{II}) \rightarrow \mathrm{Cu}(\mathrm{I})$ reduction, so a copper(II) salt is the obvious starting point. Catalyst/reoxidant systems of this type are well known ${ }^{[23]}$ and the reoxidant effectiveness of oxygen has been noted. [22a] Serendipitously, a very clean reaction ensued when 16a was exposed to $\mathrm{Pd}(\mathrm{OAc})_{2} / \mathrm{CuCl}$ in acetonitrile at $70^{\circ} \mathrm{C}$

\begin{tabular}{|c|c|c|c|c|}
\hline Entry & Pd salt & Cu salt & $\begin{array}{c}\text { Full } \\
\text { consumption of } \\
16 a ?\end{array}$ & $\begin{array}{l}\text { Yield of } \\
18 a(\%)\end{array}$ \\
\hline 1 & $\mathrm{Pd}(\mathrm{OAc})_{2}$ & None & No & $0^{[\mathrm{b}]}$ \\
\hline 2 & $\mathrm{Pd}(\mathrm{OAc})_{2}$ & $\mathrm{CuCl}$ & Yes & 52 \\
\hline 3 & $\mathrm{Pd}(\mathrm{OAc})_{2}$ & $\mathrm{CuCl}_{2}$ & Yes & $0^{[c]}$ \\
\hline 4 & $\mathrm{Pd}(\mathrm{OAc})_{2}$ & CuOAc & Yes & $0^{[d]}$ \\
\hline 5 & $\mathrm{Pd}(\mathrm{OAc})_{2}$ & $\mathrm{Cu}(\mathrm{OAc})_{2}$ & Yes & 39 \\
\hline 6 & $\mathrm{PdCl}_{2}$ & $\mathrm{CuCl}$ & No & 11 \\
\hline 7 & $\mathrm{PdCl}_{2}$ & CuOAc & Yes & $0^{[e]}$ \\
\hline 8 & $\mathrm{PdCl}_{2}$ & $\mathrm{Cu}(\mathrm{OAc})_{2}$ & Yes & 40 \\
\hline 9 & None & $\mathrm{CuCl}$ & No & $0^{[f]}$ \\
\hline
\end{tabular}
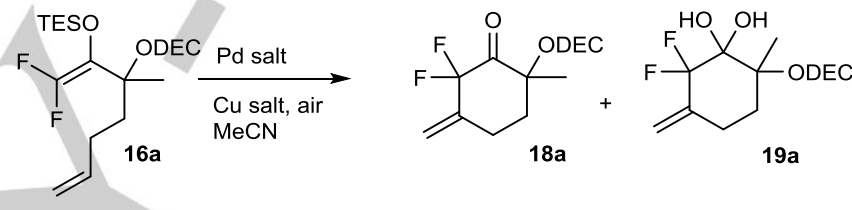

Table 2. $\mathrm{Pd} / \mathrm{Cu}$ salt combinations investigated for the Saegusa-Ito cyclisation of $16 a^{[a]}$

[a] All reactions were carried out with $1.0 \mathrm{mmol}$ of $\mathbf{1 6 a}$ [b] The major product was 17 (16a:17 30:65); traces of 18a and other products were detected. [c] A complex mixture of products obtained. [d] Though 18a was detected, it could not be isolated; 17 was also formed. [e] Though 18a was detected, it could not be isolated. [f] Traces of $\mathbf{2 0}$ and $\mathbf{2 1}$ (vide infra) were detected.

The copper salt was reagent grade and very pale green in colour indicating the presence of small amounts of copper(II) salt. We were able to isolate a mixture of $18 a$ and $19 a$ in $49 \%$ combined yield by evaporating the reaction mixture onto silica and purifying by flash column chromatography. While the ${ }^{19} \mathrm{~F}$ NMR 
spectrum was ambiguous because of the presence of very broad signals for the hydrate, the ${ }^{13} \mathrm{C}$ NMR spectrum of the mixture showed two complete sets of signals, with one ketonic $\mathrm{C}=\mathrm{O}$ signal and one highly deshielded $s p^{3}$-derived signal, both clearly split by two fluorines. Hydrate $19 a$ crystallized and the molecular structure was revealed by $\mathrm{X}$-ray crystallographic analysis (Figure 3). The (N,N-diethylcarbamoyloxy) group occupies the pseudo-axial position allowing the more demanding methyl group to take an equatorial position. ${ }^{[24]}$
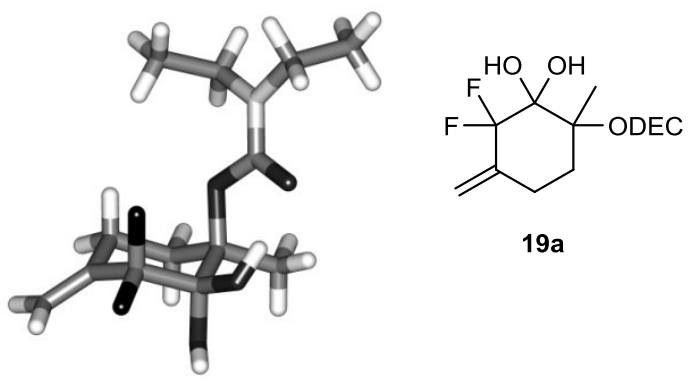

Figure 3. Molecular structure of 19a in the crystal.

However, this structure opposes fluorine and oxygen atoms in diaxial positions, within the sum of their van der Waals radii, which must have an energetic cost. Closer inspection of the structure revealed some twisting of the ring to allow the axial C$\mathrm{O}$ and $\mathrm{C}-\mathrm{F}$ bonds to diverge, and the heteroatoms to move slightly further apart.

Though fluoroketone hydration is well known, ${ }^{[25]}$ the reaction is reversible and there is relatively little water in our reactions (none is introduced in the work-up); intramolecular hydrogen bonding may help to stabilize the hydrate. Rigorous removal of metal salts was achieved by eluting the crude reaction mixture through celite with diethyl ether, and treating the ethereal solution of the crude product with scavenger silica (see the Supporting Information for details) for ca. 30 minutes. This resulted in effective sequestration of the metal contaminants. Removal of the ether solvent from the crude product afforded an oil, which could be triturated with pentane to afford crystalline product directly, removing the need for chromatography at this stage. Pure solid ketone could be isolated by drying the mixture in a vacuum oven, allowing reliable yields to be quoted.<smiles>C=CCCC(C)(OCC)C(=O)C(F)(F)F</smiles>

20<smiles>C=CCC/C(C)=C(\OC)C(F)(F)OC(=O)OC</smiles>

21a $(E)$ and $21 \mathbf{b}(Z)$
Figure 4. Potential and independently synthesised side products of the cyclisation reactions.
Using this procedure, 18 a could be isolated in $52 \%$ yield under $\mathrm{Pd}(\mathrm{OAc})_{2} / \mathrm{CuCl}$ conditions. Initial experiments with copper(II) salts were discouraging. In the presence of $\mathrm{Pd}(\mathrm{OAc})_{2} / \mathrm{CuCl}_{2}, 16 \mathrm{a}$ was transformed to a complex reaction mixture in which cyclic products could not be detected. Copper(II) chloride reacts as a chlorine electrophile with silyl enol ethers ${ }^{[26]}$ and we were able to prepare $\mathbf{2 0}$ in good yield from 16a under the published conditions (see the Supporting Information). Surprisingly, we were not able to detect $\mathbf{2 0}$ in the cyclisation mixture.

Table 3: Palladium catalyzed cycloalkenylations of silyl enol ethers. ${ }^{[a]}$

Silyl enol
ether

[a] Unless otherwise stated all reactions were carried out with $1.0 \mathrm{mmol}$ of $\mathbf{1 6}$ [b] Only 22 could be isolated cleanly from the reaction. [c] $1.23 \mathrm{mmol}$ of $16 \mathrm{e}$ was used. [d] $1.23 \mathrm{mmol}$ of $\mathbf{1 6 g}$ was used. [e] $0.91 \mathrm{mmol}$ of $\mathbf{1 6 h}$ was used. [f] $0.66 \mathrm{mmol}$ of $16 \mathbf{i}$ was used. [g] $1.22 \mathrm{mmol}$ of $16 \mathbf{j}$ was used. [h] $1.67 \mathrm{mmol}$ of $16 \mathrm{k}$ was used. [i] The reaction time was $144 \mathrm{~h}$.

Better results were obtained with copper(II) acetate, with either palladium(II) acetate or the dichloride salt (39 and $40 \%$ yields respectively) but the highest yielding system was consistently $\mathrm{Pd}(\mathrm{OAc})_{2} / \mathrm{CuCl}$. Air oxidation of this copper $(\mathrm{I})$ salt may be required before the active reoxidant is formed, so the concentration of copper(II) species is expected to be low. While this will attenuate the unwanted electrophilic chlorination, it should also limit the rate of reoxidation, which would be undesirable. The full range of silyl enol ethers was then exposed to the $\mathrm{Pd}(\mathrm{OAc})_{2} / \mathrm{CuCl}$ conditions to test the generality of the 
cyclisation and isolation procedure (Table 3); a range of cyclic ketones and other products was isolated.

With stoichiometric copper(I) chloride, the palladium(II) loading could be reduced to $5 \%$ in some cases. Reducing the Pd loading further usually led to the recovery of difluoromethyl ketones after slow consumption of the silyl enol ethers. The reactions could be run open to the air after sparging the acetonitrile immediately before use with air; an atmosphere of pure oxygen was unnecessary, though the reactions were faster when placed under an atmosphere of oxygen (see the Supporting Information for details). The use of higher reaction temperatures (80 or 90 ${ }^{\circ} \mathrm{C}$ ) offered no advantage Lowering the loading of copper salt also reduced the rate of conversion significantly, and lowered the quality of the final product, even when the reactions were run under pure oxygen, and in acetonitrile which contained added water at levels which optimise oxygen solubility in the solution phase. ${ }^{[27]}$ One readily identifiable type of impurity was formed in these very slow cyclisation reactions; initially, we mis-assigned signals at ca. $-70 \mathrm{ppm}$ in the ${ }^{19} \mathrm{~F}$ NMR spectrum as $\mathbf{2 0}$, though splitting patterns were inconsistent with the presence of diastereotopic fluorine atoms.

Thermal [3,3]-rearrangement of $\mathbf{1 6 a}$ immolates the stereogenic centre and forms a pair of silyl enol ether diastereoisomers 21a and $\mathbf{2 1 b}$ in which the fluorine atoms are equivalent. While there is a strong driving force for this type of rearrangement (vide supra), the kinetic barrier to rearrangement appears to be sufficiently high to allow material to flow down the cyclisation pathway. It seems unlikely that either transition metal salt catalyses this rearrangement ${ }^{[28]}$ or it would form the major pathway under these conditions. Microwave irradiation of $16 \mathbf{a}$ $\left(120{ }^{\circ} \mathrm{C}, 8\right.$ hours) secured the same mixture of rearrangement products confirming the relevance of the thermal conditions.<smiles>C=COC1CCC(C=O)=C(F)C1=O</smiles><smiles>C=C(C)CCC(C)(O[C+](C)=O)C(=O)C(F)(F)F</smiles>

23

Figure 5. Side products formed in slow cyclisation reactions.

However, only traces of $\mathbf{1 8 d}$ could be detected from the attempted cyclisation of $\mathbf{1 6 d}$ (prepared from pentenal); the major product was enal $22(8 \%)$, as revealed by NMR correlation spectroscopy, calculation of the ${ }^{19} \mathrm{~F}$ NMR chemical shift $\left(\delta_{\mathrm{F}}\left(\mathrm{CDCl}_{3}\right)=-131.0 \mathrm{ppm}\right.$, calculated ${ }^{[29]} \mathrm{EDF} 2 / 6-31 \mathrm{G}^{*}\left(\delta_{\mathrm{F}}\left(\mathrm{CDCl}_{3}\right)\right.$ $=-132.4 \mathrm{ppm}$ ) and literature precedent. ${ }^{[30]}$ The formation of enal 22 could involve a Wacker-type process on product 18d; though the Wacker reaction has recently been modified to allow aldehyde synthesis, ${ }^{[31]}$ the hydroxypalladation step normally follows Markovnikoff regiochemistry and forms ketones from terminal alkenes, but $\mathrm{CF}_{2}$ is a powerfully electron-withdrawing substituent and may reverse the normal regiochemistry in the

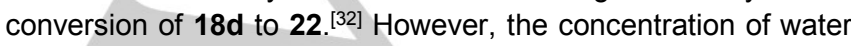
in our reaction mixtures is likely to be quite low, making the conversion of $\mathbf{1 8 d}$ to $\mathbf{2 2}$ very slow. The addition of gem-dimethyl groups (at $\mathrm{C}_{\alpha}$ ) allowed an efficient cyclisation of $16 \mathrm{e}$ to $18 \mathrm{e}$ but internal and terminal methylation prevented the cyclisation reaction, with 23 recovered from $16 c$, and a complex reaction mixture returned from $16 \mathrm{~b}$. We were disappointed to fail to force dienyl species $16 f$ to cyclise, and were also surprised at the rather slow reaction of cyclopropyl congener $16 \mathrm{~g}$. We could cyclise $16 \mathbf{i}-160$ successfully to afford the bicyclic ketones $18 \mathbf{i}-$ 180; these annelative reactions were the fastest observed and could be carried out at the lowest loadings of $\mathrm{Pd}(\mathrm{II})$. Though the silyl enol ethers were formed as mixtures of cis- and transdiastereoisomers, the trans-fused products which form from the major diastereoisomer were usually isolated and are therefore shown in the Table. Exceptionally, sulfone 180 was isolated as a mixture of trans- and cis- bicyclic ketones (trans:cis $87: 13$ by GC and ${ }^{1} \mathrm{H}$ NMR), which reflected closely the ratio of diastereoisomers in starting material 16o (84:16). The sulfonyl motif is an attractive one to include in the cyclic products because of its use as a bioisostere ${ }^{[33]}$ for the carbonyl group. ${ }^{[34]}$ Sulfide 16n (from 15n) cyclised very slowly; sulfide coordination to palladium(II) would impair activation of either alkenyl group. Stahl and co-workers ${ }^{[35]}$ have reported that DMSO coordinates strongly to $\mathrm{Pd}(\mathrm{II})$ through sulfur and our sulfide is likely to be more Lewis basic. Oxidation of the sulfide precursor to the sulfone 150 and elaboration allowed the successful synthesis of 180.

Saegusa-Ito cyclisations often produce a mixture of alkene regioisomers with the alkenyl group moving into conjugation with the carbonyl group. We assume that the cyclisation forms 24 which undergoes $\beta$-hydride elimination to form 25 and then 18a, the less stable exocyclic alkene kinetic product. The formation of $\mathrm{HPdX}$ species means that there is potential for equilibration via hydropalladation to form 26. ${ }^{[36]}$ In the gas phase, 27 was $3.2 \mathrm{kcal}$ $\mathrm{mol}^{-1}$ less stable $(\Delta \mathrm{E})$ than $\left.18 \mathrm{a}, \Delta \mathrm{G}=4.3 \mathrm{kcal} \mathrm{mol}^{-1}\right)$, while in acetonitrile (Truhlar and Cramer's SM8 method ${ }^{[37]}$ was used with single point calculations), $18 \mathrm{a}$ was $4.0 \mathrm{kcal} \mathrm{mol}^{-1}$ less stable $(\Delta \mathrm{E})$ than 27 (Scheme 4).

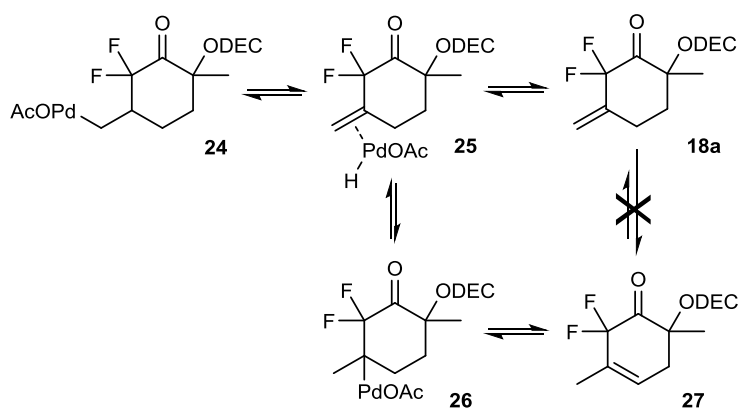

Scheme 4. Kinetic (18a) and thermodynamic (27) products of cyclisation and potential linking palladium complexes.

Electronic structure calculations (B3LYP/6-31G*) were carried out to confirm the anticipated energy difference between 18a and the potential thermodynamic product 27 . The energy difference is decisive and there is a clear driving force for isomerisation; the persistence of $\mathbf{1 8 a}$ is therefore surprising. 
However, the terminal alkenyl group in 18a is expected to be a better ligand for a $\mathrm{Pd}(\mathrm{II})$ species than either the exocyclic or endocyclic alkenes; ${ }^{[38]}$ only if the HPdOAc complex dissociates readily from product $\mathbf{2 5}$, and is oxidised more rapidly than it can rebind and hydropalladate the exocyclic alkene to afford 26, can the persistence of the kinetic product be explained. We found a very limited number of examples of annulations carried out by this type of palladium-catalysed method. Saegusa and coworkers reported the formation of a number of cyclopentenones when a range of silyloxy 1,5-dienes were exposed to stoichiometric $\mathrm{Pd}(\mathrm{OAc})_{2}$ in acetonitrile at room temperature. One catalytic procedure (benzoquinone was the reoxidant) was reported while a $\mathrm{Cu}(\mathrm{OAc})_{2} / \mathrm{O}_{2}$ combination was ineffective. However, cyclohexenone homologues were formed in only $36 \%$ yield under the stoichiometric conditions; alkene isomerisation occurred to move the alkene into conjugation with the carbonyl group. All the examples of catalytic reactions which we have been able to find in the literature involve annelations, which benefit from lower reaction entropies. Our annulative cyclisation therefore represents a significant extension of what the methodology can deliver. The $\mathrm{Pd}(\mathrm{OAc})_{2} / \mathrm{Cu}(\mathrm{OAc})_{2}$ conditions are interesting because Speziali and co-workers ${ }^{[39]}$ point out that the redox potentials of the relevant $\mathrm{Pd}$ and $\mathrm{Cu}$ ions are not compatible under chloride-free conditions. Even then, the process is still quite strongly endergonic. ${ }^{[0]}$ More complex reoxidation processes involving bimetallic species in some cases ${ }^{[41]}$ are known but further discussion lies outwith the scope of this manuscript. Finally, the starting oxidation state of the copper salt requires comment; it might be assumed that copper(II) salts would be the most effective additives because they would already be present in the correct oxidation state, whereas the copper(I) species would require oxidation before entering the cycle. However, Stahl and co-workers have noted that oxidations of alcohols which rely on a copper(II) active species turn over more rapidly when the active species is made in situ from a copper(I) salt, than when a copper(II) salt is added directly. ${ }^{[42]}$ To develop some insight into the effectiveness of cyclisation, we calculated the thermodynamics of the reaction shown below (Figure 6). We carried out Monte Carlo searches (MMFF94) to identify the lowest energy species using the Equilibrium Conformer algorithm in Spartan'08. We reduced the trialkyl silyl group from triethyl- to trimethyl-, and the carbamate from $\mathrm{N}, \mathrm{N}$-diethyl- to $\mathrm{N}, \mathrm{N}$-dimethyl- (ODMC) to cut down on the number of conformers which the search algorithm would be required to examine. The geometries were then optimised (B3LYP/6-31G*) with full frequency calculations. These simple calculations suggest strongly that the cyclisations of the relatively highly substituted systems we have examined have a significant energetic advantage over the cyclisation of the prototypical diene 28a to 29a examined by Saegusa; as the cyclisation and $\mathrm{Pd}$ recycle reactions are coupled, this advantage may account for our success in establishing the oxidative turnover. The introduction of the carbamoyloxy group favoured cyclisation strongly. Adding a methyl group amplified the effect and the introduction of $\mathrm{CF}_{2}$ provided an additional significant driving force. O'Hagan and co-workers have observed an experimental advantage to cyclopentene formation by RCM when a $\mathrm{CF}_{2}$ centre is present, and carried out calculations to show that there is a significant enthalpic component to the advantage. ${ }^{[43]}$

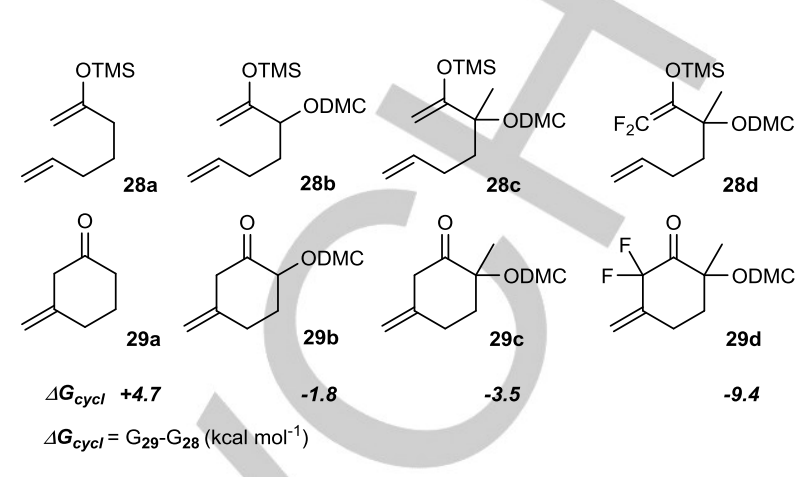

Figure 6. Calculated free energies of cyclisation, $\Delta \mathrm{G}_{c y c l}=\mathrm{G}_{29}-\mathrm{G}_{28}$ (B3LYP/6$31 \mathrm{G}^{*}$ (gas phase, $\left.298 \mathrm{~K}\right) / \mathrm{kcal} \mathrm{mol}^{-1}$, normalised to $\mathrm{Me}_{3} \mathrm{SiH}$ ), $-\mathrm{ODMC}=-$ $\mathrm{OCONMe}_{2}$.

The effects of gem-disubstitution (particularly with dialkyl groups) are well-known and have been documented thoroughly. ${ }^{[44]}$ Other computational aspects of the reaction will be examined elsewhere.

\section{Conclusions}

The method described in this manuscript represents an extremely concise way of building difluorinated cyclohexenones (three steps from trifluoroethanol). Precursors are assembled in a single step and are easy to purify, and the cyclisations are easy to perform in reaction vessels open to the air; the use of molecular dioxygen is not required, though it could be used to accelerate cyclisation. Cyclic ketone products were obtained in high purity without chromatography. While annelations were generally effective, annulations required a fairly high level of substitution (though not on the terminal alkenyl group). The Failure of $\mathbf{1 8 d}$ to form under catalytic conditions was disappointing. The reaction products are rich in functionality, structurally unusual and difficult to access by other means so this represents a significant expansion of the repertoire applicable to the synthesis of selectively difluorinated molecules.

\section{Experimental Section}

General Experimental: NMR spectra were recorded on Bruker DPX-400, AV-500 and Avance-II+ 600 spectrometers. ${ }^{1} \mathrm{H},{ }^{19} \mathrm{~F}$ and ${ }^{13} \mathrm{C}$ NMR spectra were recorded using the deuterated solvent as the lock and the residual solvent as the internal reference. The multiplicities of the spectroscopic data are presented in the following manner: $s=$ singlet, $d=$ doublet, $d d=$ double doublet, $\mathrm{dt}=$ doublet of triplets, $\mathrm{ddt}=$ doublet of double triplets, $\mathrm{t}=$ triplet, $\mathrm{q}=$ quartet, $\mathrm{m}=$ multiplet and $\mathrm{br}$. = broad. Unless stated otherwise, all couplings refer to ${ }^{3} \mathrm{~J}$ homocouplings. All ${ }^{1} \mathrm{H}$ spectra are fully assigned. IR spectra were recorded on an ATR IR spectrometer. GC/MS spectra were obtained on an instrument fitted with a DB5-type column (30 $\mathrm{m} \times$ $0.25 \mu \mathrm{m}$ ) running a $40-320{ }^{\circ} \mathrm{C}$ temperature program, ramp rate $20{ }^{\circ} \mathrm{C}$ 
min ${ }^{-1}$ with helium carrier gas flow at $1 \mathrm{~cm}^{3} \mathrm{~min}^{-1}$. Chemical ionisation (Cl) (methane) mass spectra were recorded on an Agilent Technologies 5975C mass spectrometer. HRMS measurements were obtained from a Waters GCT Premier MS (Cl), Finnigan Mat 95 XP (EI-MS and/or APClMS), or Thermo Scientific LTQ Orbitrap XL via Advion TriVersa NanoMate infusion (NSI-ES) spectrometers (EPSRC National Mass Spectrometry Service Centre, Swansea). Thin layer chromatography was performed on pre-coated aluminium-backed silica gel plates (E. Merck AG, Darmstadt, Germany. Silica gel 60 F254, thickness $0.2 \mathrm{~mm}$ ). Visualisation was achieved using potassium permanganate or UV detection at $254 \mathrm{~nm}$. Column chromatography was performed on silica gel (Zeochem, Zeoprep 60 HYD, 40-63 $\mu \mathrm{m}$ ) using a Büchi Sepacore system. Hexane was distilled before chromatography. Metal salts $\left(\mathrm{Pd}(\mathrm{OAc})_{2}\right.$ (reagent grade, $98 \%$ ), $\mathrm{CuCl}$ (ReagentPlus $\left.{ }^{\circledR}, \geq 99 \%\right), \mathrm{CuCl}_{2}$ (97\%), CuOAc (97\%), CuOAc2 (98\%), $\mathrm{PdCl}_{2}(\geq 99.9 \%)$ ) were purchased from Sigma Aldrich and used as received. THF was dried using a PureSolv system from Innovative Technology, Inc.. All other chemicals were purchased from Sigma Aldrich, Apollo Scientific, Alfa Aesar, or Fluorochem. Details of the electronic structure calculations are contained in the Supporting Information.

\section{Preparation of 16a (general procedure for silyl enol ether preparation}

Carbamate 10 (0.88 mL, 5 mmole) was added dropwise over 5-6 minutes at $-78^{\circ} \mathrm{C}$ by syringe to a stirred solution of LDA $(6.7 \mathrm{~mL}$ of a 1.5 $\mathrm{M}$ solution in tetrahydrofuran/heptane/ethylbenzene, $10.0 \mathrm{mmole}$ ) in THF $(11 \mathrm{~mL})$. The clear brown solution was stirred for 2 hours at $-78{ }^{\circ} \mathrm{C}$, clearing to a dark orange solution during this time. Ketone $15 \mathrm{a}(0.54 \mathrm{~g}$, $5.5 \mathrm{mmole}$ ) was added neat in a stream over 1 minute. The mixture was stirred at $-78{ }^{\circ} \mathrm{C}$ for 1 hour while the brown colour faded to yellow or orange, then brought to $0{ }^{\circ} \mathrm{C}$ in an ice bath over 1 hour further. Chlorotriethylsilane $(0.84 \mathrm{~mL}, 5 \mathrm{mmole})$ was added in one portion. The yellow solution was allowed to warm slowly to room temperature $\left(15^{\circ} \mathrm{C}\right)$ overnight. After 18 hours, the mixture was concentrated under reduced pressure $\left(40{ }^{\circ} \mathrm{C}, 150-75 \mathrm{mmHg}\right.$, then $\left.0.1 \mathrm{mmHg}\right)$ to remove the THF, then treated with hexane $(10 \mathrm{~mL})$ to precipitate lithium salts. The suspension was transferred by pipette onto a pad of silica gel $(10 \mathrm{~g})$, which had been conditioned with $10 \%$ diethyl ether in hexane, in a sinter funnel (30 $\mathrm{mm}$ diameter). The crude product was eluted by washing with $10 \%$ diethyl ether in hexane $(200 \mathrm{~mL})$ and the eluent was evaporated under reduced pressure to afford crude silyl enol ether $16 \mathbf{a}(1.3 \mathrm{~g})$ as a mobile clear yellow oil. The crude silyl enol ether was purified by flash column chromatography (90 g silica, $10 \%$ diethyl ether in hexane) to afford $16 \mathrm{a}$ as a colourless oil $(1.31 \mathrm{~g}, 67 \%) ; R_{f}=0.25$ (5\% ethyl acetate in hexane); ${ }^{1} \mathrm{H}$ NMR $\left(400 \mathrm{MHz}, \mathrm{CDCl}_{3}\right): \delta=5.82$ (ddt, $J=16.7,10.2,6.6 \mathrm{~Hz}$ $1 \mathrm{H}$ ), $5.07-4.99$ ( $\mathrm{m}$ incl. app. d, $J=16.7 \mathrm{~Hz}, 1 \mathrm{H}$ ), 4.98-4.92 (m incl. app. d, $J=10.1 \mathrm{~Hz}, 1 \mathrm{H}), 3.42-3.07(\mathrm{~m}, 4 \mathrm{H}), 2.16-2.01(\mathrm{~m}, 2 \mathrm{H}), 1.99-1.88(\mathrm{~m}, 2 \mathrm{H})$ $1.61\left(\mathrm{~d},{ }^{5} \mathrm{JH}-\mathrm{F}=4.0 \mathrm{~Hz}, 3 \mathrm{H}\right), 1.10(\mathrm{t}, J=7.1 \mathrm{~Hz}, 6 \mathrm{H}), 0.97(\mathrm{t}, J=7.9 \mathrm{~Hz}$, $9 \mathrm{H}), 0.73-0.64 \mathrm{ppm}(\mathrm{m}, 6 \mathrm{H}) ;{ }^{13} \mathrm{C} \mathrm{NMR}\left(125 \mathrm{MHz}, \mathrm{CDCl}_{3}\right): \delta=154.0$, $153.6\left(\mathrm{dd},{ }^{1} \mathrm{~J}_{\mathrm{C}-\mathrm{F}}=284.1,279.8 \mathrm{~Hz}\right), 138.2,115.7\left(\mathrm{dd},{ }^{2} \mathrm{~J}_{\mathrm{C}-\mathrm{F}}=32.3,16.7\right.$ $\mathrm{Hz}), 114.5,80.1\left(\mathrm{t},{ }^{3} \mathrm{JC}_{\mathrm{C}}=3.5 \mathrm{~Hz}\right), 41.3^{*}, 38.1,28.1,22.3\left(\mathrm{~d},{ }^{4} \mathrm{JC}_{\mathrm{C}-\mathrm{F}}=6.9\right.$ $\mathrm{Hz}), 13.9,13.4,6.6,5.1 \mathrm{ppm} ;{ }^{19} \mathrm{~F}$ NMR $\left(376 \mathrm{MHz}, \mathrm{CDCl}_{3}\right): \delta=-102.1(\mathrm{~d}$ $\left.{ }^{2} J_{\mathrm{F}-\mathrm{F}}=86.9 \mathrm{~Hz}, 1 \mathrm{~F}\right),-112.0\left(\mathrm{dq},{ }^{2} J_{\mathrm{F}-\mathrm{F}}=86.9 \mathrm{~Hz},{ }^{5} J_{\mathrm{F}-\mathrm{H}}=4.0 \mathrm{~Hz}, 1 \mathrm{~F}\right) \mathrm{ppm}$; $\bar{v} /($ film $)=2957,1703,1418,1258,1169 \mathrm{~cm}^{-1}$; HRMS (NSI): calcd for $\mathrm{C}_{19} \mathrm{H}_{36} \mathrm{~F}_{2} \mathrm{NO}_{3} \mathrm{Si}, 392.2427[\mathrm{M}+\mathrm{H}]^{+}$, found: $392.2427 ; \mathrm{MS}(\mathrm{Cl}): \mathrm{m} / \mathrm{z}(\%):$ 392 (22) $[\mathrm{M}+\mathrm{H}]^{+}, 362$ (9) $\left[\mathrm{M}-\mathrm{C}_{2} \mathrm{H}_{5}\right], 350$ (19) $\left[\mathrm{M}-\mathrm{C}_{3} \mathrm{H}_{5}\right], 100$ (100) [CONEt 2 ]. *Both $\mathrm{CH}_{2}$ carbons appear at this chemical shift.

\section{Preparation of 18a and 19a}

Palladium(II) acetate $(10 \mathrm{~mol} \%, 57.5 \mathrm{mg}$ ) and copper(I) chloride (100 $\mathrm{mol} \%, 252 \mathrm{mg}$ ) were suspended in dry acetonitrile $(5 \mathrm{~mL})$ that had been sparged with oxygen for thirty minutes through a drawn out pipette. The suspension was added via syringe to a solution of silyl enol ether $\mathbf{1 6 a}$ $(2.55 \mathrm{mmol}, 1.0 \mathrm{~g})$ in dry acetonitrile $(10 \mathrm{~mL})$. The mixture was then stirred at $45{ }^{\circ} \mathrm{C}$ for 72 hours under balloon pressure of oxygen. The reaction mixture was evaporated under reduced pressure onto silica, and the residue was then loaded onto a silica pad. Crude product was eluted from the silica with $0-25 \%$ ethyl acetate in hexane then concentrated under reduced pressure to afford a pale yellow oil. Purification by flash chromatography $(0-40 \%$ diethyl ether in petroleum ether) afforded an inseparable mixture of cyclic ketone $18 \mathrm{a}$ and hydrate $19 \mathrm{a}$ as a pale yellow oil $(345 \mathrm{mg}, 49 \%)$. Hydrate 19a crystallised from the mixture stored overnight at $5{ }^{\circ} \mathrm{C}$. Crystals were washed with cold diethyl ether before recrystallising by dissolving in refluxing diethyl ether and allowing pentane vapour diffusion into the solution overnight: data for ketone 18a are reported below. For hydrate 19a: m.p. $83-85^{\circ} \mathrm{C} ; R_{f}=0.25(40 \%$ diethyl ether in petroleum ether); ${ }^{1} \mathrm{H} \mathrm{NMR}\left(500 \mathrm{MHz}, \mathrm{CDCl}_{3}\right): \delta=6.26$ (br. $\mathrm{s}, 1 \mathrm{H}), 5.50\left(\mathrm{~d},{ }^{4} \mathrm{~J}\right.$-F $\left.=0.5 \mathrm{~Hz}, 1 \mathrm{H}\right), 5.20\left(\mathrm{~d},{ }^{4} \mathrm{~J}\right.$-F $\left.=1.0 \mathrm{~Hz}, 1 \mathrm{H}\right), 5.06$ (br. s, $1 \mathrm{H})$, 3.30-3.18 (m, $4 \mathrm{H}), 2.58-2.51(\mathrm{~m}, 1 \mathrm{H}), 2.32-2.29(\mathrm{~m}, 1 \mathrm{H}), 2.01-1.87$ $(\mathrm{m}, 2 \mathrm{H}), 1.66(\mathrm{~s}, 3 \mathrm{H}), 1.16 \mathrm{ppm}\left(\mathrm{t},{ }^{3} \mathrm{~J}_{\mathrm{H}-\mathrm{F}}=7.1 \mathrm{~Hz}, 6 \mathrm{H}\right) ;{ }^{13} \mathrm{C}$ NMR $(125$ $\left.\mathrm{MHz}, \mathrm{CDCl}_{3}\right): \delta=156.5,139.3\left(\mathrm{t},{ }^{2} \mathrm{~J}_{\mathrm{C}-\mathrm{F}}=19.8 \mathrm{~Hz}\right), 117.4\left(\mathrm{t},{ }^{1} \mathrm{~J}_{\mathrm{C}-\mathrm{F}}=251.4\right.$ $\mathrm{Hz}), 113.9\left(\mathrm{t},{ }^{3} \mathrm{JC}_{\mathrm{C}-\mathrm{F}}=7.9 \mathrm{~Hz}\right), 94.2\left(\mathrm{t},{ }^{3} \mathrm{JC}_{\mathrm{C}-\mathrm{F}}=24.0 \mathrm{~Hz}\right) 42.3,42.2,36.1$, 26.6, 19.2, 13.9, $13.3 \mathrm{ppm} ;{ }^{19} \mathrm{~F} \mathrm{NMR}\left(376 \mathrm{MHz}, \mathrm{CDCl}_{3}\right): \delta=(-115.1)-(-$ 116.8) (broad, 1F), (-118.1)-(-120.7) ppm (broad, 1F); $\bar{v} /($ film) $=3331$, 1694, 1657, $1079 \mathrm{~cm}^{-1}$; LRMS (ES): $\mathrm{m} / \mathrm{z} 316.2(100)[\mathrm{M}+\mathrm{Na}]^{+}, 294.1$ (25) $[\mathrm{M}+\mathrm{H}]^{+}$; HRMS (ES-TOF): calcd for $\mathrm{C}_{13} \mathrm{H}_{22} \mathrm{~F}_{2} \mathrm{NO}_{4} 294.1511[\mathrm{M}+\mathrm{H}]^{+}$, found 294.1507; elemental analysis calcd (\%) for $\mathrm{C}_{13} \mathrm{H}_{21} \mathrm{~F}_{2} \mathrm{NO}_{4}$ : C, 53.23; $\mathrm{H}$, 7.22; N, 4.78. Found: $\mathrm{C}, 53.28 ; \mathrm{H}, 7.46 ; \mathrm{N}, 4.74 .{ }^{*}$ The NMR data were extracted from the spectrum of a mixture of $18 \mathrm{a}$ and $19 \mathrm{a}$ (see the Supporting Information); crystals of 19a equilibrate to the mixture when taken up in $\mathrm{CDCl}_{3}$. See below for the NMR dataset for pure 18a which hydrates slowly in dry $\mathrm{CDCl}_{3}$.

The relative stereochemistry and identity of hydrate $19 \mathrm{a}$ were confirmed by XRD analysis; Crystal data: $\mathrm{C}_{13} \mathrm{H}_{21} \mathrm{~F}_{2} \mathrm{NO}_{4}$, crystal size $0.25 \times 0.22 \times$ $0.10 \mathrm{~mm}^{3}, M=293.31$, monoclinic, space group $\mathrm{P} 2{ }_{1} / \mathrm{c}$, unit cell dimensions $a=11.4871(3), b=12.5419(3), c=10.1805(2) \AA, \alpha=90^{\circ}, \beta$ $=97.055(2)^{\circ}, y=90^{\circ}, V=1455.60(6) \AA^{3}, Z=4, D_{\text {calc }}=1.338 \mathrm{Mg} \mathrm{m}^{-3}$, $F(000)=624, \mu(\mathrm{Mo}-\mathrm{K} \alpha)=0.114 \mathrm{~mm}^{-1}, T=123(2) \mathrm{K}, 7123$ total reflections measured, 3178 independent, $\left(R_{\text {int }}=0.0205\right)$ which were used in all calculations. Final $R$ indices (for reflections with $I>2 \sigma(I)$ ) were $R 1=$ $0.0326, \omega R 2=0.0711 ; R$ indices (all data) $R 1=0.0522, \omega R 2=0.0740$

Preparation of 18a (general procedure for palladium-catalysed cyclisation)

Palladium(II) acetate (10 mol\%, $22.4 \mathrm{mg}$ ) and copper (I) chloride (100 $\mathrm{mol} \%, 99 \mathrm{mg}$ ) were suspended in dry acetonitrile $(4 \mathrm{~mL})$ that had been sparged with air for 30 minutes through a drawn out pipette. The suspension was warmed to $70^{\circ} \mathrm{C}$ then a solution of silyl enol ether $16 \mathrm{a}$ $(1.00 \mathrm{mmol}, 0.391 \mathrm{~g})$ in dry acetonitrile $(1.6 \mathrm{~mL})$ added via syringe in a constant stream. The mixture was then stirred at $70{ }^{\circ} \mathrm{C}$ for 18 hours under an air condenser and open to the atmosphere. The reaction mixture was concentrated and transferred by pipette onto a plug of celite. The product was eluted from the celite with diethyl ether $(50 \mathrm{~mL})$. The crude product was taken up in diethyl ether $(10 \mathrm{~mL})$ and PhosphonicS STA3 scavenger silica was added. The mixture was stirred for 30 minutes, then the mixture filtered through a $20 \mu \mathrm{m}$ polyethylene frit and washed with diethyl ether $(50 \mathrm{~mL})$. The solvent was removed under reduced pressure to afford crude product as an oil. Trituration in pentane afforded a granular colourless solid which was dried in a vacuum oven $\left(40^{\circ} \mathrm{C}, 0.75 \mathrm{mmHg}, 48\right.$ hours $)$ to afford ketone $18 \mathrm{a}(0.141 \mathrm{~g}, 52 \%) \cdot \mathrm{R}_{\mathrm{f}}=$ 0.25 (40\% diethyl ether in petroleum ether); ${ }^{1} \mathrm{H}$ NMR $\left(400 \mathrm{MHz}, \mathrm{CDCl}_{3}\right)$ : m.p. $=52-54{ }^{\circ} \mathrm{C}$ (pentane trituration); $R_{f}=0.29(40 \%$ diethyl ether in hexane); ${ }^{1} \mathrm{H}$ NMR (400 MHz, $\mathrm{CDCl}_{3}$ ): $\delta=5.53$ (app. d, ${ }^{4} \mathrm{~J}_{\mathrm{H}-\mathrm{F}}=4.00 \mathrm{~Hz}$, $\left.\mathrm{H}_{\mathrm{a}} \mathrm{H}_{\mathrm{b}} \mathrm{C}=\mathrm{C}, 1 \mathrm{H}\right), 5.25$ (br. s, $\left.\mathrm{H}_{\mathrm{a}} \mathrm{H}_{\mathrm{b}} \mathrm{C}=\mathrm{C}, 1 \mathrm{H}\right), 3.44-3.11\left(\mathrm{~m}, \mathrm{~N}\left(\mathrm{CH}_{2} \mathrm{CH}_{3}\right)_{2}\right.$, 
$4 \mathrm{H}), \quad 2.90-2.66 \quad\left(\mathrm{~m}, \quad \mathrm{H}_{2} \mathrm{C}=\mathrm{CCH}_{a} \mathrm{H}_{\mathrm{b}}, \quad 1 \mathrm{H}\right), \quad 2.54-2.26 \quad(\mathrm{~m}$, $\left.\mathrm{H}_{2} \mathrm{C}=\mathrm{CCH}_{a} H_{b} \mathrm{CH}_{c} \mathrm{H}_{d} \mathrm{CO}, 2 \mathrm{H}\right), 1.74-1.58\left(\mathrm{~m}, \mathrm{COCH}_{\mathrm{c}} \mathrm{H}_{d}, 1 \mathrm{H}\right), 1.54(\mathrm{~s}$, $\mathrm{COCH}_{3}, 3 \mathrm{H}$ ), 1.15 (t, $\left.J=7.4 \mathrm{~Hz}, \mathrm{~N}\left(\mathrm{CH}_{2} \mathrm{CH}_{3}\right)_{2}, 3 \mathrm{H}\right), 1.09 \mathrm{ppm}$ (t, $J=7.5$ $\left.\mathrm{Hz}, \mathrm{N}\left(\mathrm{CH}_{2} \mathrm{CH}_{3}\right)_{2}, 3 \mathrm{H}\right) ;{ }^{13} \mathrm{C} \mathrm{NMR}\left(100 \mathrm{MHz}, \mathrm{CDCl}_{3}\right): \delta=194.2$ (dd, ${ }^{2} \mathrm{~J}_{\mathrm{C}-\mathrm{F}}=$ 26.0, $23.2 \mathrm{~Hz}), 154.7,141.1\left(\mathrm{t},{ }^{2} \mathrm{~J} \mathrm{C}-\mathrm{F}=20.5 \mathrm{~Hz}\right), 115.5\left(\mathrm{t},{ }^{3} \mathrm{~J}\right.$ - $\left.-\mathrm{F}=7.8 \mathrm{~Hz}\right)$, $114.2\left(\mathrm{dd},{ }^{1} \mathrm{~J} \mathrm{C}-\mathrm{F}=257.0,253.5 \mathrm{~Hz}\right), 82.1,42.0,41.5,38.2,26.5\left(\mathrm{~d},{ }^{3} \mathrm{JC}-\mathrm{F}=\right.$ $7.8 \mathrm{~Hz}), 21.5,14.0,13.2 \mathrm{ppm} ;{ }^{19} \mathrm{~F} \mathrm{NMR}\left(376 \mathrm{MHz}, \mathrm{CDCl}_{3}\right): \delta=-103.7(\mathrm{~d}$, $\left.{ }^{2} J_{\mathrm{F}-\mathrm{F}}=250.4 \mathrm{~Hz}, 1 \mathrm{~F}\right),-117.6 \mathrm{ppm}\left(\mathrm{d},{ }^{2} \mathrm{JF}_{\mathrm{F}-\mathrm{F}}=250.4 \mathrm{~Hz}, 1 \mathrm{~F}\right) ; \bar{v} /(\mathrm{film})=$ 2984, 2939, 1749, 1686, 1429, 1281, $1117 \mathrm{~cm}^{-1}$; HRMS (ES-TOF): calcd for $\mathrm{C}_{13} \mathrm{H}_{20} \mathrm{~F}_{2} \mathrm{NO}_{3}, 276.1406[\mathrm{M}+\mathrm{H}]^{+}$, found: $276.1402 ; \mathrm{MS}(\mathrm{Cl}): \mathrm{m} / \mathrm{z}(\%)$ : $304(11)\left[\mathrm{M}+\mathrm{C}_{2} \mathrm{H}_{5}\right]^{+}, 276(100)[\mathrm{M}+\mathrm{H}]^{+}, 100(94)\left[\mathrm{CONEt}_{2}\right] ; \mathrm{t}_{\mathrm{R}}(\mathrm{GC})=$ 12.64 minutes; elemental analysis calcd (\%) for $\mathrm{C}_{13} \mathrm{H}_{19} \mathrm{~F}_{2} \mathrm{NO}_{3}$ : C, 56.72; $\mathrm{H}, 6.96 ; \mathrm{N}, 5.09$; found: $\mathrm{C}, 56.62 ; \mathrm{H}, 6.72 ; \mathrm{N}, 5.10$ (pentane trituration).

\section{Acknowledgements}

We thank the Carnegie Trust for a Carnegie PhD Scholarship and Dr Vipulkumar Patel (GSK Flexible Discovery Unit) for additional support, the EPRSC National Mass Spectrometry Service Centre, Swansea for accurate mass measurements, the EPRSC National Crystallography Service, Southampton for crystal structures, and Craig Irving (NMR Technician, University of Strathclyde) for assistance with NMR experiments.

Keywords: difluoroketone $\cdot$ homogeneous catalysis $\bullet$ cyclisation - palladium • oxidation

[1] a) M. Toyota, M. Ihara, Synlett 2002, 1211; b) M. Toyota, Procedia Chem., 2014, 13, 3.

[2] F. Dénès, A. Perez-Luna, F. Chemla, Chem. Rev. 2010, 110, 2366

[3] O. F. Jeker, E. M. Carreira, Angew. Chem.-Int. Edit. 2012, 51, 3474

[4] a) J. T. S. Yeoman, V. W. Mak, S. E. Reisman, J. Am. Chem. Soc. 2013, 135, 11764; b) J. T. S. Yeoman, J. Y. Cha, V. W. Mak, S. E. Reisman, Tetrahedron 2014, 70, 4070.

[5] Y. Ito, H. Aoyama, T. Hirao, A. Mochizuki, T. Saegusa, J. Am. Chem. Soc. 1979, 101, 494

[6] M. Toyota, T. Wada, K. Fukumoto, M. Ihara, J. Am. Chem. Soc. 1998 120,4916

[7] M. Toyota, M. Rudyanto, M. Ihara, J. Org. Chem. 2002, 67, 3374.

[8] T. Mase, I. N. Houpis, A. Akao, I. Dorziotis, K. Emerson, T. Hoang, T. lida, T. Itoh, K. Kamei, S. Kato, Y. Kato, M. Kawasaki, F. R. Lang, J. M. Lee, J. Lynch, P. Maligres, A. Molina, T. Nemoto, S. Okada, R. Reamer, J. Z. Song, D. Tschaen, T. Wada, D. Zewge, R. P. Volante, P. J. Reider K. Tomimoto, J. Org. Chem. 2001, 66, 6775 .

[9] R. P. Singh, J. M. Shreeve, Synthesis 2002, 2561

[10] C. Fah, L. A. Hardegger, L. Baitsch, W. B. Schweizer, S. Meyer, D. Bur, F. Diederich, Org. Biomol. Chem. 2009, 7, 3947

[11] Y. Kageshima, C. Suzuki, K. Oshiro, H. Amii, Synlett 2015, 26, 63.

[12] a) F. Barth, C. O.-Yang, Tetrahedron Lett. 1991, 32, 5873; b) T. Morikawa, Y. Kodama, J. Uchida, M. Takano, Y. Washio, T. Taguchi, Tetrahedron 1992, 48, 8915; c) L. A. Buttle, W. B. Motherwell, Tetrahedron Lett. 1994, 35, 3995; d) P. E. Harrington, M. A. Tius, J. Org. Chem. 1999, 64, 4025; e) Y. Y. Yang, W. D. Meng, F. L. Qing, Org. Lett. 2004, 6, 4257; f) J. A. L. Miles, L. Mitchell, J. M. Percy, K. Singh, E. Uneyama, J. Org. Chem. 2007, 72, 12; g) T. Anderl, C. Audouard, A. Miah, J. M. Percy, G. Rinaudo, K. Singh, Org. Biomol. Chem. 2009, 7, 5200; h) D. Orr, J. M. Percy, T. Tuttle, A. R. Kennedy, Z. A. Harrison, Chem.-Eur. J. 2014, 20, 14305.

[13] a) O. Lefebvre, T. Brigaud, C. Portella, Tetrahedron 1998, 54, 5939; b) O. Lefebvre, T. Brigaud, C. Portella, J. Org. Chem. 2001, 66, 1941; c) F.
Chorki, B. Crousse, D. Bonnet-Delpon, J. P. Bégué, T. Brigaud, C. Portella, Tetrahedron Lett. 2001, 42, 1487.

[14] J. S. Yu, Y. L. Liu, J. Tang, X. Wang, J. Zhou, Angew. Chem.-Int. Edit 2014, 53, 9512.

[15] a) S. Jonet, F. Cherouvrier, T. Brigaud, C. Portella, Eur. J. Org. Chem 2005, 4304; b) W. Kashikura, K. Mori, T. Akiyama, Org. Lett. 2011, 13 1860; c) C. Xie, L. Wu, H. Mei, V. A. Soloshonok, J. Han, Y. Pan, Org. Biomol. Chem. 2014, 12, 7836

[16] Y. Guo, J. M. Shreeve, Chem. Commun. 2007, 3583.

[17] a) C. Guo, R. W. Wang, F. L. Qing, J. Fluorine Chem. 2012, 143, 135; b) G. B. Ma, W. Wan, Q. Y. Hu, H. Z. Jiang, J. Wang, S. Z. Zhu, J. Hao Chem. Commun. 2014, 50, 7527; c) S. Z. Ge, W. Chaladaj, J. F. Hartwig, J. Am. Chem. Soc. 2014, 136, 4149; d) Z. Feng, Q. Q. Min, Y. L. Xiao, B. Zhang, X. G. Zhang, Angew. Chem.-Int. Edit. 2014, 53, 1669

[18] a) H. Greuter, R. W. Lang, A. J. Romann, Tetrahedron Lett. 1988, 29, 3291 ; b) K. Uneyama, K. Maeda, T. Kato, T. Katagiri, Tetrahedron Lett. 1998, 39, 3741.

[19] A. S. Balnaves, T. Gelbrich, M. B. Hursthouse, M. E. Light, M. J. Palmer, J. M. Percy, J. Chem. Soc., Perkin Trans. 1 1999, 2525.

[20] A. J. Kresge, Accounts Chem. Res. 1990, 23, 43.

[21] J. Gao, J. O. Simon, R. Rodrigo, A. Assoud, J. Org. Chem. 2013, 78, 48.

[22] a) R. C. Larock, T. R. Hightower, J. Org. Chem. 1993, 58, 5298; b) R. VanBenthem, H. Hiemstra, J. J. Michels, W. N. Speckamp, J. Chem. Soc., Chem. Commun. 1994, 357.

[23] E. M. Beccalli, G. Broggini, M. Martinelli, S. Sottocornola, Chem. Rev 2007, 107, 5318.

[24] E. L. Eliel, S. H. Wilen, L. N. Mander, Stereochemistry of Organic Compounds, Wiley-Interscience, New York, 1994.

[25] J. P. Guthrie, J. Am. Chem. Soc. 2000, 122, 5529

[26] Y. Ito, M. Nakatsuka, T. Saegusa, J. Org. Chem. 1980, 45, 2022.

[27] Q. Li, C. Batchelor-McAuley, N. S. Lawrence, R. S. Hartshorne, R. G. Compton, J. Electroanal. Chem. 2013, 688, 328

[28] a)L. E. Overman, Angew. Chem.-Int. Ed. Engl. 1984, 23, 579; b) A. G. Jamieson, A. Sutherland, C. L. Willis, Org. Biomol. Chem. 2004, 2, 808.

[29] Spartan'08, Wavefunction, Irvine, CA, 2008.

[30] C. Gonzalez-Bello, M. K. Manthey, J. H. Harris, A. R. Hawkins, J. R. Coggins, C. Abell, J. Org. Chem. 1998, 63, 1591.

[31] a) P. Teo, Z. K. Wickens, G. Dong, R. H. Grubbs, Org. Lett. 2012, 14 , 3237; b)Z. K. Wickens, K. Skakuj, B. Morandi, R. H. Grubbs, J. Am Chem. Soc. 2014, 136, 890.

[32] M. M. Lerch, B. Morandi, Z. K. Wickens, R. H. Grubbs, Angew. Chem.Int. Edit. 2014, 53, 8654

[33] N. A. Meanwell, J. Med. Chem. 2011, 54, 2529.

[34] K. Vandyck, M. D. Cummings, O. Nyanguile, C. W. Boutton, S. Vendeville, D. McGowan, B. Devogelaere, K. Amssoms, S. Last, K. Rombauts, A. Tahri, P. Lory, L. Hu, D. A. Beauchamp, K. Simmen, P. Raboisson, J. Med. Chem. 2009, 52, 4099.

[35] T. N. Diao, P. White, I. Guzei, S. S. Stahl, Inorg. Chem. 2012, 51, 11898.

[36] a) A. S. Kende, B. Roth, P. J. Sanfilippo, T. J. Blacklock, J. Am. Chem Soc. 1982, 104, 5808; b) M. J. Hilton, L. P. Xu, P. O. Norrby, Y. D. Wu O. Wiest, M. S. Sigman, J. Org. Chem. 2014, 79, 11841.

[37] A. C. Chamberlin, C. J. Cramer, D. G. Truhlar, J. Phys. Chem. B 2008 $112,8651$.

[38] a) F. R. Hartley, Chem. Rev. 1973, 73, 163; b) G. Pregagli, F. Conti, B Minasso, J. Organomet. Chem. 1973, 47, 165

[39] a) M. G. Speziali, P. A. Robles-Dutenhefner, E. V. Gusevskaya Organometallics 2007, 26, 4003; b) M. G. Speziali, V. V. Costa, P. A Robles-Dutenhefner, E. V. Gusevskaya, Organometallics 2009, 28 3186.

[40] J. Tsuji, Palladium reagents and catalysts: innovations in organic synthesis, Wiley, Chichester, 1995

[41] a) T. Hosokawa, S. I. Murahashi, Accounts Chem. Res. 1990, 23, 49, b) C. N. Cornell, M. S. Sigman, Inorg. Chem. 2007, 46, 1903; c) D. 
Harakat, J. Muzart, J. Le Bras, RSC Advances 2012, 2, 3094; d) Y.-Y. Jiang, Q. Zhang, H.-Z. Yu, Y. Fu, ACS Catalysis 2015, 5, 1414.

[42] a) J. M. Hoover, S. S. Stahl, J. Am. Chem. Soc. 2011, 133, 16901; b) J. M. Hoover, B. L. Ryland, S. S. Stahl, J. Am. Chem. Soc. 2013, 135 , 2357.
[43] C. A. Urbina-Blanco, M. Skibinski, D. O'Hagan, S. P. Nolan, Chem. Commun. 2013, 49, 7201.

[44] M. E. Jung, G. Piizzi, Chem. Rev. 2005, 105, 1735. 
Entry for the Table of Contents (Please choose one layout)

Layout 2:

\section{FULL PAPER}

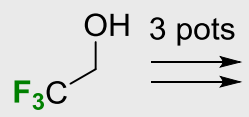<smiles>C=C1CCC(C)(OC(=O)OCC)C(=O)C1(F)F</smiles>

1 distillation

1 column

1 crystallisation

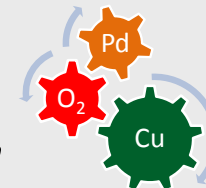

Run rings around fluorine Palladium(II)-catalysed cycloalkenylation (SaegusaIto cyclisation) has been used for the first time to transform difluorinated silylenol ethers to difluorinated cycloalkenones under mild conditions. The silylenol ether precursors were prepared in two high-yielding steps from trifluoroethanol, and cyclised in moderate to good yields.
Prof. Dr. Jonathan M. Percy, *Adam W. McCarter, Alan L. Sewell, N. Sloan, Dr. Alan R. Kennedy, and Dr. David J. Hirst.

Page No. - Page No.

Developing the Saegusa-Ito Cyclisation for the Synthesis of Difluorinated Cyclohexenones 